\title{
A REAÇÃO DE UHLENHUTH EM MEDICINA=LEGAL
}

\author{
ARNALDO AMADO FERREIRA \\ Docente-Livre, $1^{\circ}$ Assistente, Chefe de Lab. do Depart. de Medicina
Legal da Fac. de Med. da Universidade de S. Paulo \\ ,
}

Dentre as reações biológicas empregadas na prática médico-legal, destinadas ao diagnóstico específico de sangue, salienta-se, sem dúvida, como a melhor, a sôro precipitação, tambem denominada de prova de Uhlenhuth, por ter sido êsse cientista tudesco quem primeiro a utilizou para fins forenses.

A preferência que os legistas lhe dão, justifica-se porque é segura nos resultados, simples na técnica, facil e eficiente no modo de se obterem sôros precipitantes de elevado teor em precipitinas, como se requer em medicina legal.

1 - O primeiro cientista que observou o fenômeno precipitante foi Kraus, em 1897.

Ao imunizar coelhos com culturas microbianas, notou que os sôros dêsses animais, quando postos em contacto com os caldos de cultura que serviram para as inoculações, provocavam o aparecimento dum precipitado de colorido esbranquiçado que, aos poucos, se depositava no fundo do tubo. O precipitado aparecia, no ínicio, sob a forma de anel, no limite separativo dois líquidos em presença.

Depois de Kraus, seguiram as observações de Bordet com leite aquecido à temperatura de $65^{\circ} \mathrm{C}$. que, injetado em coelhos, produziu um sôro que precipitava a albumina do leite. Ainda, a seguir, Gengòu imunizou coelhos com leite de cabra, carneiro, vaca e notou que os sôros dêstes animais só precipitavam as albuminas dos leites com os quais foram inoculados.

Tschstowitch, em 1899, preparou animais com sôro de enguia e obteve um precipitado quando postos juntos antisôro e o sôro do referido animal. Foi, ainda, êsse pesquisador que chamou atenção para as albumino-precipitinas.

Entretanto, cabe a Uhleuhuth a primazia da aplicação médico legal da sôro precipitação. Uhlenhuth preparou os primeiros sôros anti-humanos e os experimentou em dezenove espécies de animais e demostrou que só reagiam quando os sôros anti-humanos eram postos em contacto com o sôro e sangue humanos e não com os outros. Ademais, continuando suas experiências, realizou uma série de inte- 
ressantes pesquisas com manchas de sangue em vários suportes e não se esquecera de praticar a prova com sangue putrefeito.

Em todas essas experiências, provou a especificidade da reação, o que permitiu a introdução das zoo-precipitinas na prática forense.

\section{2 - NATUREZA DA REAÇÃO}

As precipitinas, conforme Kolmer, são anticorpos específicos que se formam no sôro dos animais inoculados com batérias, soluções de albuminas vegetais ou animais e que adquiriram o poder de precipitar uma solução de albumina ou de filtrado de cultura com o qual foram injetados.

O sôro inoculado contem uma su'bstância com função antigênica que se denomina - precipitinogênio, que produz no animal um anticorpo específico chamado - precipitina, que adquire a propriedade de precipitar as proteinas.

Sôbre o mecanismo da reação muito se tem escrito áfim de elucidá-1o. Das teorias aventadas para explicá-lo duas são as mais aceitas - a química, das cadeias laterais, de Ehrlich, a física, de Bordet, que considera a reação como de carater coloidal e, parece, a que reune maior número de prosélitos.

\section{3 - PREPARAC̨ÃO DO SÔRO PRECIPITANTE}

Problema de interêsse para o legista é o da preparação do sôro precipitante, pois abrange um série de questões práticas que não deve desconhecer e que são as que se seguem:

a) Escolha do animal produtor de sôro. Várias são as espécies de animais que se recomendam como produtores de sôro precipitante - o coelho, o cobaio, o carneiro, a cabra, o cão, o boi e o cavalo. Entretanto, nos institutos médico legais, o animal de escolha é o coelho, porque é fácil de se obter, procria com rapidez, fornece sôro cm quantidade e qualidade suficiente. O cobaio foi aconselhado, mas os resultados não o recomendaram.

O cavalo, o boi, a cabra e o carneiro foram propostos para êsse fim, porém como são animais de grande porte, necessitando de muito sôro para ser imunizados, o seu preço elevado, dificuldade de mantê-los no laboratório, são fatos que os fązem regeitados. Todavia, o cavalo é ótimo produtor de sôro, mas só utilizado nos grandes institutos, onde se tem necessidade de uma produção avantajada de sôro. Os coelhos empregados na produção de sôro, devem. ser novos, ter atingido o seu completo desenvolvimento, o seu pêso nunca deve ser inferior a dois quilos. Há raças que são melhores produtoras de sôro do que outras. Existem animais que, a-pesar-de injetados reiteradas vezes, mesmo usando-se as vias inoculatórias mais variądas, não produzem sôro de título suficiente. A nossa prática tem de- 
mostrad̀ que a produção de um bom sôro precipitante depende mais da espécie, da raça, da qualidade do animal, que do processo utiiizado e da via seletiva empregada. No Instituto Oscar Freire temos observado que os coelhos que fornecem melhor sôro são os de pêlo cinzen'o, escuro; preto e malhado. Os coelhos albinos nã̃o são bons produtores.

b) Número de animais a inocular-se. O técnico jamais imunizará ưn só animal, mas lotes de quatro a seis. Isso porque há animais que, no correr das inoculações, morrem, outros emagrecem e adoecem e, ainda, há os que não fornecem sôro de título elevado, mesmo que se reiterem as inoculações.

c) Matcrial a ser empregado. Raramente se inoculam animais com sangue "in natura". Preferem-se sôros ou uma solução de cocto-antÍgenos.

O sôro pode obter-se por vários modos. O meio mais recomendável é recolher-se o sangue de uma das veias da face anterior do cotovêlo. Dez centímetros cúbicos são suficientes para se conseguir sôro em quantidade desejada. Colhido o sangue e formado o coágulo, com bastão de vidro esterilizado desloca-se o mesmo das paredes do tubo e leva-se o mesmo a geladeira por 12 a 18 horas. No dia imediato, o sôro que sobrenada é separado e, se não estiver bem límpido, será centrifugado antes de injetado nos animais.

Há quem recomende o emprêgo dos líquidos ascítico, pleurítico, cístico, a urina albumininosa, para com êles se imunizarem os coelhos. Tais líquidos só em casos excepcionais deverão utilizar-se.

Para se preparar os cocto-antígenos, empréga-se a técnica de Dalla Volta e Del Cárpio.

Tomam-se 10.c.c. de sôro humano que se diluem em 10c.c. de agua distilada e se adicionam 5 gramas de sulfato de amônio e 5 gotas de ácidó acético.

Coloca-se tudo num balão de boca larga, leva-se ao banho maria e se deixa ferver até que as albuminas se precipitem. Filtra-se em funil de vidro com papel de filtro; o resíduo que fica no papel é sêco ao calor ambiente, ou na estufa de $37^{\circ}$, ou no vácuo.

Os cócto-antígenos podem támbem preparar-se com sangue de cadaver, conforme estudos de Manuel Pereira, em 1933, no Instituto Oscar Freire. A técnica é a mesma que a precedente, só que o sangue será colhido das carótidas ou diretamente do coração do cadáver.

Aquí, a "causa mortis" não altera a qualidade do antígeno e nem atúa nocivamente, quando inoculado nos animais.

d) Vias de inoculação Os animais podem ser inoculados pelas vias subcutâneas, intraperitoneal e endovenosa.

$1^{\circ}$ - Via Subcutânea - E' a mais demorada para a obtenção de um sôro precipitante. Sua técnica é simples. Um ajudante mantem o animal, nêste caso a coelho, pelas patas anteriores e posteriores, colocando-o com o abdome para cima. No abdome, no ponto escolhido, raspa-se o pêlo, a pele é desinfetada pelo alcool ou pela 
tintura de iodo. Toma-se a pele entre o polegar e o indicador esquerdo, suspendendo-a um pouco, de modo que forme uma dobra. Com a mão direita introduz-se a agulha, que será fina, obliquamente, e o sôro é injetado vagarosamente. Isso feito, retira-se a agulha, procede-se ligeira massagem no ponto de inoculação, afim de se estabelecer o paralelismo dos planos dos tecidos atravessados pela agulha $\mathrm{e}$ se evitar o refluxo do líquido. Fig. n. ${ }^{\circ} 1$.

$2 .^{\circ}$ - Injeção intraperitoneal - Como para caso precedente, o animal será mantido pelas pernas anteriores e posteriores, com o abdome para cima e a cabeça para baixa, afim de que a massa intestinal tenda para o diafragma. Depois de raspado o pêlo da região obdominal lateral no ponto escolhido, toma-se a pele com o polegar e o indicador esquerdos, alevanta-se a mesma e a agulha é introduzida

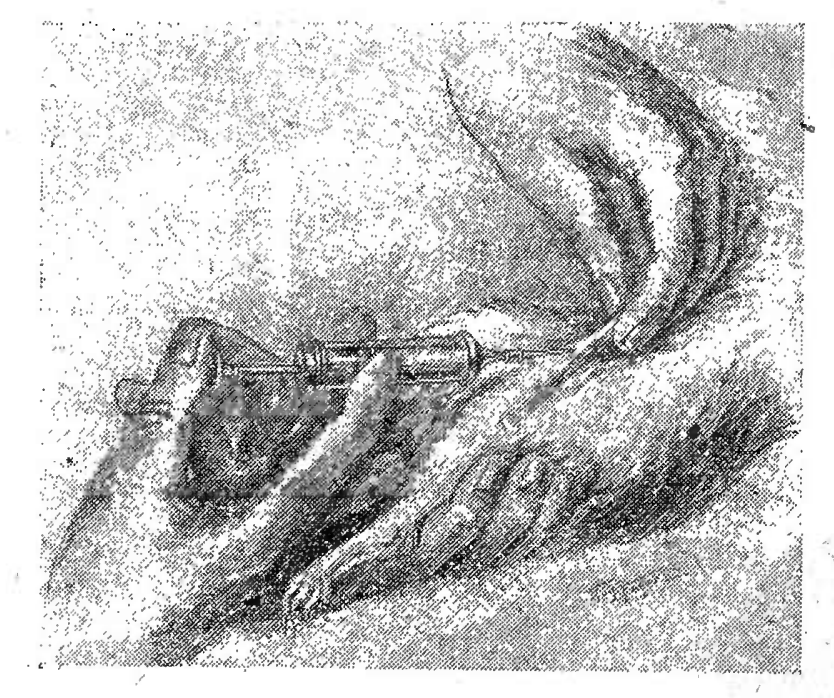

FIG. 1

Técnica de injeção subcutânea (Kolmer).

na base da dobra da pele, procurando-se atingir a cavidade peritoneal. A agulha deve ser curta. Percebe-se que atingiu a cavidade pela facilidade com que a agulha se desloca no seu interior. O sôro é injetado de vagar. E' escusado dizer que o material devé ser esterilizado e o sôro asséptico. Fig. n. ${ }^{\circ} 2$.

$3 .^{\circ}$ - Injeção endovenosa - A inoculação pela via endovenosa é mais delicada do que pelas precedentes. O animal, para isso, será mantido numa goteira apropriada, ou numa caixa, tendo apenas a cabeça para fóra. Fig. 3. O ponto de preferência para as injeçôes são as veias marginais das orelhas do coelho.

Há animais em que não são bem visiveis, fazendo-se necessário o emprego de meios que as tornem patentes. Para isso, é aconselhavel que sejam elas irritadas pela agua quente, pela esfregação com um pouco de xilol, meios êsses que provocarão forte congestão ativa das mesmas e os vasos se evideciam. A agulha será de calibre fino 
para não traumatizar demasiado as paredes do vaso. $\mathrm{O}$ animal uma vez imobilizado, fixa-se a orelha com a mâo esquerda, fig. n. ${ }^{0} 3$, expondo-a pela sua face dorsal e o operador introduz a agulha na direção da corrente de retorno, isto é, na direção da base da orelha. Feita a injeção, retira-se a agulha e tampona-se o local com algodão embebido numa solução de líquido Dakin.

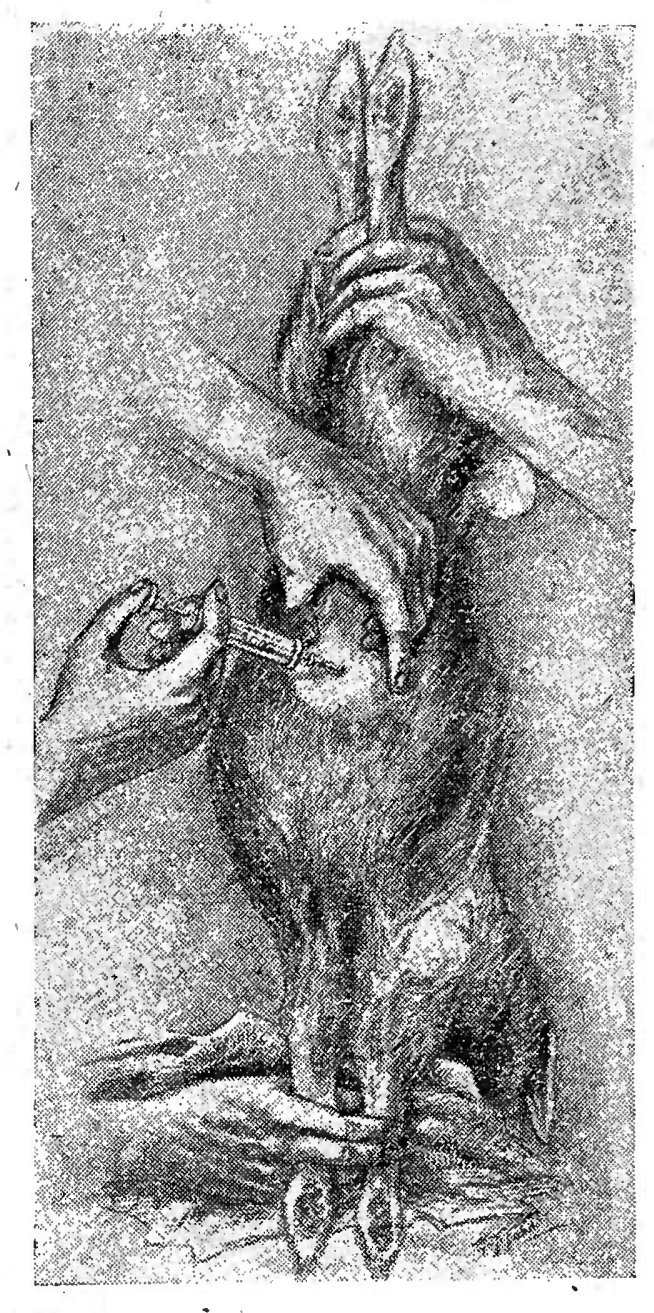

FIG. 2

Técnica da injeção intraperitonial (Kolmer).

e) Métodos de imunização - Os autores divergem quanto aos métodos de imunização a adotar-se. Geralmente as divergências são consequentes ao desejo de conseguir um processo bem eficiente na produção do sôro, rapidez no tempo de imunização dos animais e que seja menos nocivo aos mesmos.

1. ${ }^{\circ}$ - Assim, por exemplo, Nutall recomenda inocular-se endovenosamente 3 a 5 c. c. de sôro humano, de quatro em quatro ou cinco em cinco dias, e sangría dos animais no $15 .^{\circ}$ dia após a última injeção.

$2 .^{\circ}$ - Hektoem manda que se inocule, por via endovenosa, 1 a 2 c. c. de sôro, de seis em seis dias e, seis dias depois, 4 a 5 c. c. de sôro intraperitonialmente, quatro a cinco vezes, com intervalo de 
seis dias entre cada injeção e sangría dos animais no $90^{\circ}$ dia depois da última inoculação.

$3 .^{\circ}$ - Uhlenhuth injetava nos coelhos 2 a 3 c. c. de sôro por via endovenosa cada 5 dias por três vezes. Mandava que se verificasse o poder precipitante do sôro séte dias após a última inoculação e, depois, diariamente, curante dois a três dias. Sangrar definitivamente se o sôro atingir a titulo suficiente.

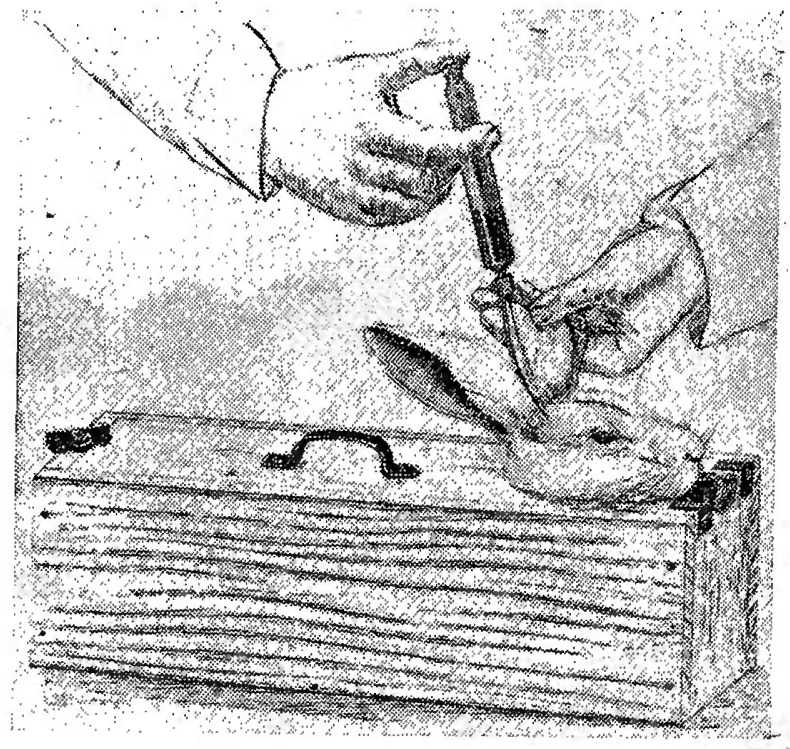

FIG. 3

Técnica da injeção endovenosa (Roy Krackẹe).

$4 .^{\circ}$ - Kolmer usa injetar $1 / 2$ c.c. de sôro, diariamente, durante três semanas. A.sangria de prova é praticada dez dias depois da última inoculação. Se o sôro não doseou convenientemente, Kolmer aconselha mais seis injeções diárias. Esse A. afirma que a mortandade de animais, por êste método, é pequena e com êle se obtem excelente sôro.

5. - Ainda', Kolmer recomenda outro método que se pode denominar - mixto - que é o seguinte:

Fazem-se quatro injeções endovenosas de 3 c. c. de sôro, três intraperitoniais de 10 c.c., com três dias de intervalo para as primeiras e cinco para as segundas. Dez dias mais tarde, depois da última injeção, o sôro será colhido e doseado. Se, porém, o seu título não atingir gráu suficiente, as inoculações se repetirão e nova sangria se fará ao fim dêste tempo.

6. - No Instituto "Oscar Freire", usamos injetar o sôro humano em doses crescentes que vai dêsde $1 / 2$ c. c. até 5 c. c., na proporção de 10 doses de meio em meio centímetro cúbico. No décimo dia após a ultima injeção, fazemos a sangria de prova e se o sôro apresenta título de $1 / 20.000$, ou mais, sangramos os animais definitivamente. Se, por acaso, o sôro não atingiu àquele título, fazemos mais três inoculações, en dias alternados, de três centímetros 
cúbicos e, no oitavo dia, nova sangria será feita. Êste metodo fornece bom sôro precipitante.

$7 .^{\circ}$ - Método dos cocto-antígenos. - Entretanto, a nosso vêr, o melhor processo para se obter um bom sôro precipitante, é o dos cocto-antígenos, que empregamos constantemente no Instituto Oscar Freire de São Paulo. Imuisiona-se 1 grama de cocto-antígeno em 10 c. c. de solução fisiológica esterilizada, que é inoculada na cavidade peritonial do animal, com agulha grossa e curta: Basta uma única injeção. Oito ou dez dias depois pratica-se a primeira sangría e a primeira doseagem do sôro que, nesta ocasião, deve atingir a $1 \%$. No $200^{\circ}$ dia, geralmente, o sôro atinge a título elevado, superior a $1 / 20.000$. Se, todavia, no vigésimo dia o sồro continuar com título insuficiente, reingeta-se o animal com a metade da dose anteriormente inoculada e, dez dias depois, nova sangría e nova doseagem. Como já dissemos, as inoculações do cocto-antígenos devem fazer-se com agulha grossa, para evitar a obstrução de sua luz pelas partículas de albumina em suspensão. Aconselhamos, quando isso acontecer, conforme experiências com Manuel Pereira, no Instituto Oscar Freire, a emulsão dos antígenos cozidos em óleo de oliva esterilizado, pois este veículo não altera o material e nem impede a produção de anticorpos precipitantes.

f) Métodos de sangría. Feita a sangría de prova, verificado que o. título do sôro atingiu a $1 / 20.000$ e mais, proceder-se-à a sangria definitiva dos animais. Para êsse fim, vários são os processos aconselhados. Quando o sôro atinge a ùm titulo muito alto, $1 / 50.000$,

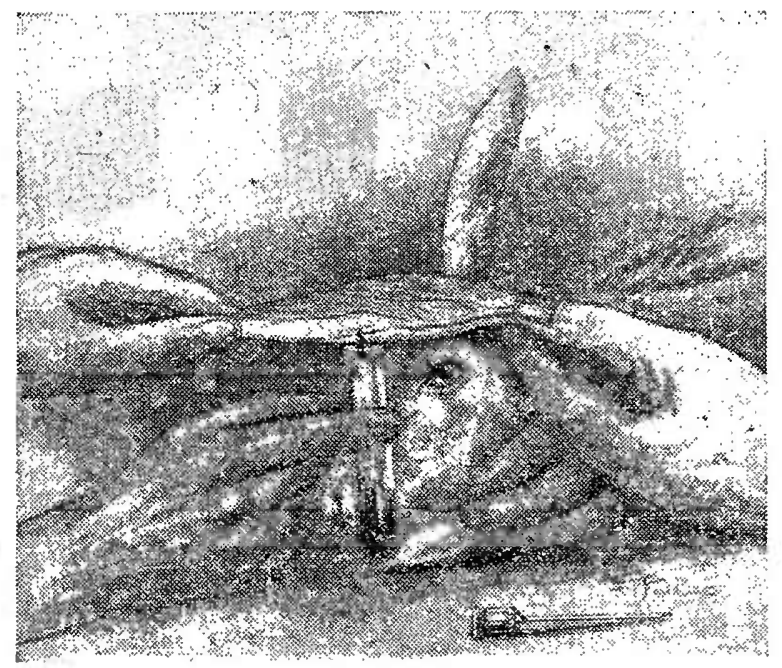

FIG. 4

Retirada do sangue por picada da veia marginal da orelha do coelho (Kolmer).

1/60.000, é aconselhavel retirar-se a maior quantidade de sangue possivel, sem, contudo, esgotar-se completamente o animal. Entanto, há técnicos que costumam, nêstes casos, sacrificar o animal. Acha- 
mos mais acertado, dêsde que o animal seja excelente produtor de sôro, não sacrificá-lo.

$10^{\circ}$ - Método para a obtenção de pequena quantidade de Sangue. - Quando se deseja obter pouco sangue, 10 a 15 c.c., é aconselhavel retirá-lo da veia marginal de uma das orelhas do coelho. Para isso, passa-se um pouco de xilol na orelha do animal e provoca-se uma congestão ativa da mesma. Com um pouco de agua morna limpa-se a orelha e com uma agulha grossa punciona-se a veia marginal, tendo o cuidado de comprimir o vaso na base da orelha, evitando a circulação de retôrno. Retirada a agulha, o sangue gotejará com facilidade e será recebido num tubo de prova esterilizado. Terminada a operação, descomprime-se o vaso junto à base da orelha e coloca-se um tampão de algodão embebido em líquido Dakin no ponto operatório. Fig. n. 4.

De outro lado, desejando-se grande quantidade de sangue, podem empregar-se os processos adiante.

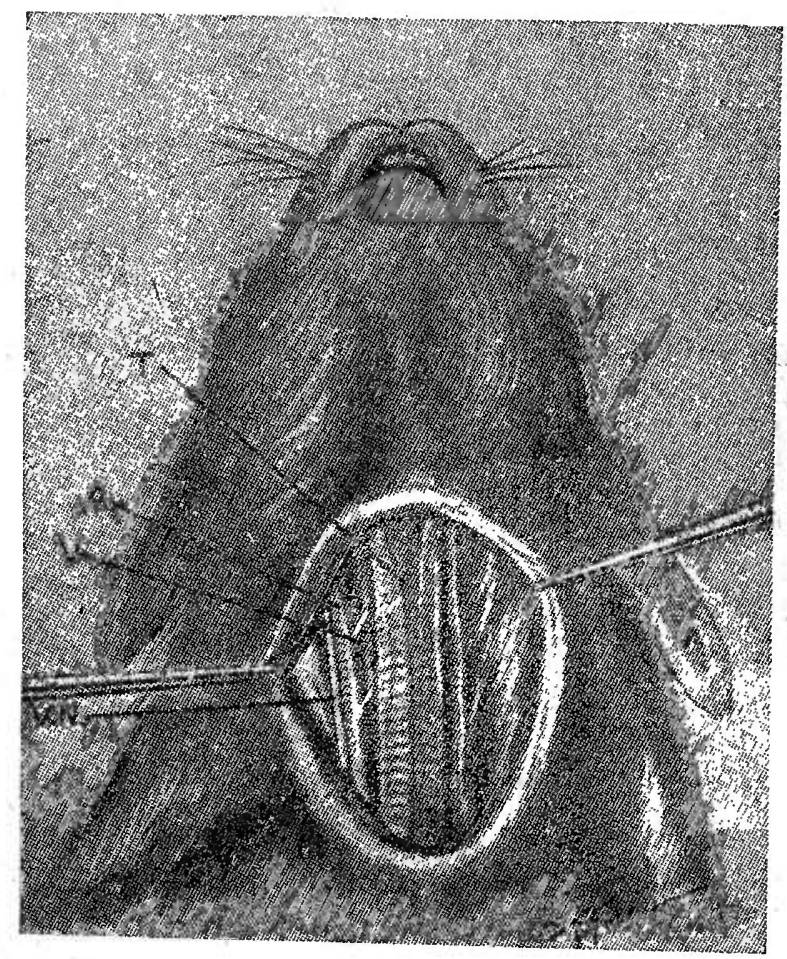

FIG. 5

A face anterior do pescoço do coelho foi incisada na linha mediana e os órgãos do pescoço sāo visiveis.

$\mathrm{T}=$ Traquea $; \mathrm{A}=$ Arteria carótida.

$\mathrm{V}=$ Veia jugular interna.
$\mathrm{VN}=$ Nervo Vago.

Processo de Nutall.

(Kolmer)

Antes de se proceder à sangria dos animais, muitos autores recomendam que sejam anestesiados. Outros, porém, acham a anestesia desnecessária. Kolmer, por exemplo, aconselha como anesté- 
sico o éter ou uma solução de alcool a $1 / 10$, que será introduzida na porção superior do reto. A solução do medicamento acima provocará sono rápido no animal e por várias horas.

$2:^{\circ}$ - Método de Nutall - $\mathrm{O}$ animal será mantido numa goteira ou seguro firmemente por um ajudante. $O$ pêlo do pescoço será raspado e a pele desinfetada pelo alcool ou pela tintura de iodo. -Depois, com bisturí afiado inicisa-se a pele do pescoço do coelho, na linha mediana, de modo que os músculos fiquem bem expostos. Um ajudante manterá o coelho de cabeça para baixo, sôbre uma cuba de vidro, ou sôbre um funil largo introduzido num tudo de prova de capacidade de 50 c. c.. O operador puxa a cabeça do animal para trás, distende o pescoço e secciona os vasos, sem, todavia, ofender a traquéa e o esôfago. O sangue será recebido no tubo e posto a coagular por 12 a 18 horas, afim de se obter o sôro desejado. Fig. 5.

3. 'Método - Pela decapitação pode-se sangrar o animal e exgotá-lo por completo. Fig. n. ${ }^{\circ} 6$.

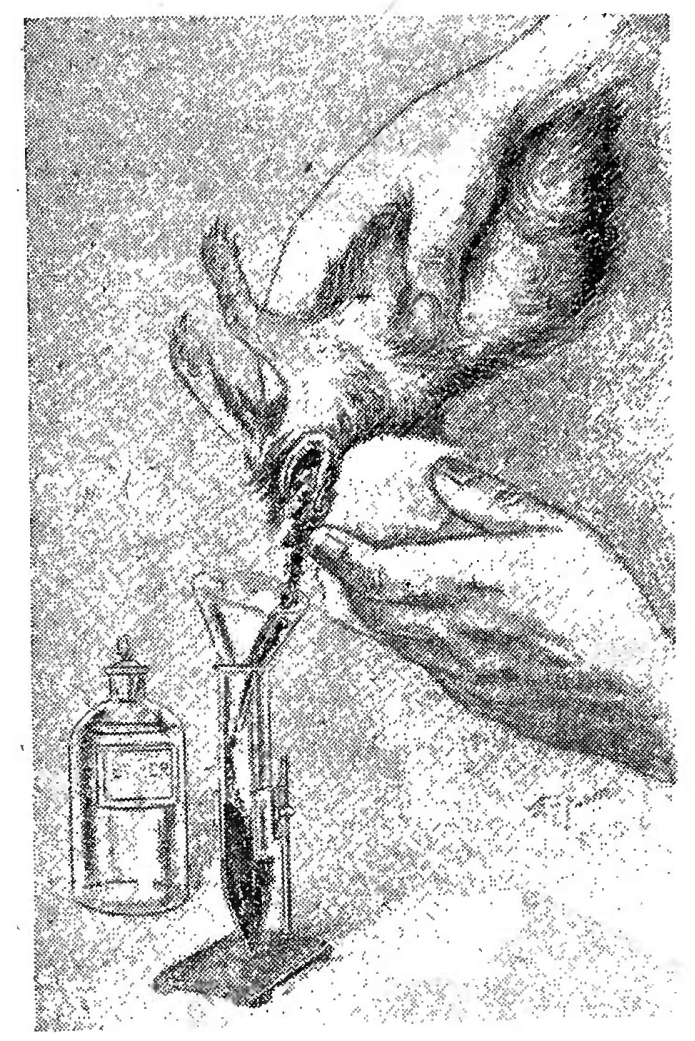

FIG. 6

Sangria por decapitação do animal.
(Kolmer).

4. - Método - O animal, uma vez colocado numa mesa operatória, sob o seu pescoço se pôe um cepo para bem distendê-lo. Fig. 7. O pêlo do pescoço é raspado e a pele desinfetada pelo iodo ou alcool. Pratica-se a incisão da pele na linha mediana, o músculo esterno-hioideo e a jugular externa são expostos. A seguir, a carótica, a jugular interna e o nervo vago são encontrados na borda ex- 
terna do músculo. Com teuta-cânula disseca-se a arteria numa extensão de 2 cents., e duas pinças hemostáticas serão colocadas na porção proximal e distal do vaso, no ponto dissecado. 'A artéria será seccionada entre as duas pinças. Na porção proximal do vaso introduz-se uma cânula de vidro que será presa por uma ligadura, tendo-se, na ocasião de introduzí-la na luz do vaso, o cuidado de retirar a pinça. A cânula de vidro se comunica com um tubo de prova, que receberá o sangue, conforme demonstra a figura anexa. Fig. 7.

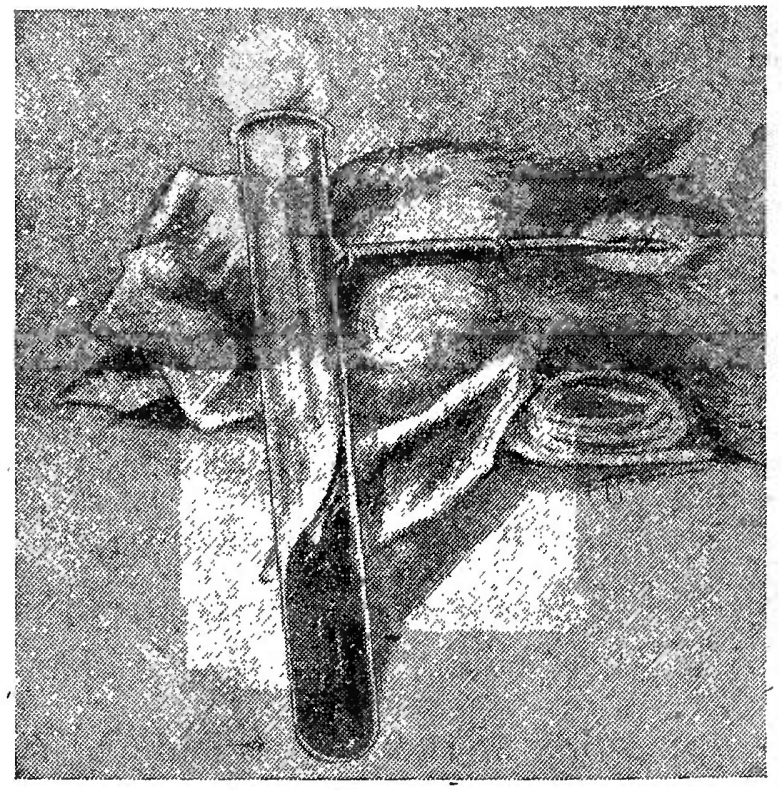

FIG. 7

4. ${ }^{\circ}$ Processo de sangria (Kolmer).

5. - Método - Este era usado por Pasteur. O coelho, depois de anestesiado, é mantido na mesa operatória. A carótica é esposta, separada dos vasos e nervos convizinhos, numa extensão de dois centímetros, colocando-se uma ligadura na parte de cima do vaso e outra, porém não apertada, na porção inferior. Com a ponta do indicador esquerdo suspende-se a arteria, introduz-se a ponta afilada de um tubo de prova através de suas paredes, na direção do coração e se recebe a quantidade de sangue desejada, isto é, 20 a 30 c. c.. Terminada a colheita do sangue, a ponta do tubo é retirada parcialmente, cerra-se a ligadura, dá-se o nó e o tubo retirado definitivamente. A ferida é suturada e o animal continua a servir para nova colheita de sangue.

6. ${ }^{\circ}$ - Método - Punção cardíaca. Finalmente, sem necessidade de anéstesia, o coelho é mantido numa goteira, ou por um ajudante, com o dorso para baixo. Raspa-se o pêlo da face anterior do torax, na altura da $4 .^{\mathrm{a}}$ e $5 .^{\mathrm{a}}$ costelas, desinfeta-se a péle comalcool ou tintura de iodo. 
$\therefore$ Pela palpação localisa-se o coração e no ponto em que os seus batimentos são mais pronunciados, na altura do $4 .^{\circ}$ ou $5 .^{\circ}$ espaço intercostais esquerdos, introduz-se uma agulha de calibre médio, de 4 cents. de comprimento através da parede toráxica até atingir a víscera, que se percebe pelo seu chocar contra a agulha. A agulha será introduzida obliquamente de cima para baixo e para dentro. Perfura-se a víscera e o sangue refluirá rapidamente na seringa, devendo fazer-se aspiração lenta. Dệste modo, com facilidade, se retiram 20 a 30 c. c. de sangue, sem que o animal pereça. Este é o processo adotado no Instituto Oscar Freire.

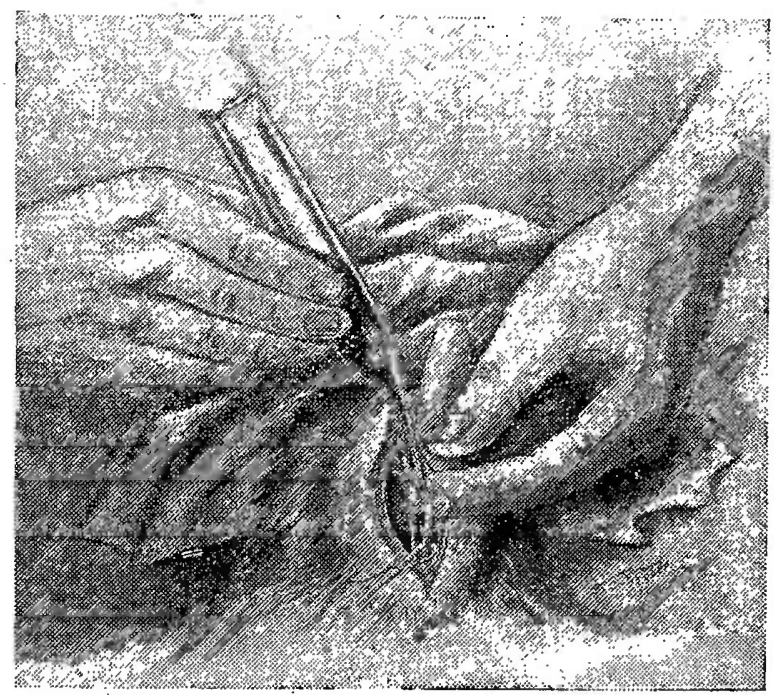

FIG. 8

Processo de sangria de Pasteur (Kolmer).

g) Conservação do sôro precipitante. No dia imediato à sangría, o sôro será guardado em ampolas esterilizadas, na quantidade de 1 c. c. por ampola. Muitos autores recomendam que se adicionem substâncias conservadoras ao sôro, como o ácido fênico a $1 \%$, o clorofórmio, floureto de sódio, timól, etc. A nossa experiência tem demonstrado que todas essas drogas turvam o sôro, no fim de certo tempo. O melhor meio de se conservar um sôro precipitante é mantê-lo na geladeira. Se, todavia, alguma das ampolas apresentarem $o$ seu conteudo turvo, antes de usá-lo, será centrifugado.

h) Doseagem do poder precipitante do sôro. Para se dosea: o poder precipitante do sôro antihumano, dilue-se o mesmo no sôro fisiológico a 8,5\%, fazendo uma série de titulações cada vez menos concentradas - a $1 \mid 10$, a $1 \mid 100$, a $1 \mid 1000$, a $1 \mid 5000$, a $1 \mid 10.000$, a $1 \mid 15.000$; a $1 \mid 20.000$, a $1 \mid 30.000$ e a $1 / 40.000$. Depois em nove pe'quenos tubos, de diametro de 3 a 4 mms. e capacidade de 1,5 c. c.. colócam-se 0,9 c. c. de cada uma das soluções acima e, do tubo de diluição menos concentrada para o mais concentrado, e 0,1 de c. c. do sồro anti-humano, cuja potência se requer determinar. Os tubos 
são levados à estufa a $37^{\circ} \mathrm{C}$. e a leitura feita dentro de 20 minutos a meia hora. O tubo de maior diluição, em que se verificar o precipitado, assinala o poder precipitante do sôro em experiencias. Fig. n. ${ }^{\circ} 9$.

Para que um sôro precipitante seja ver-

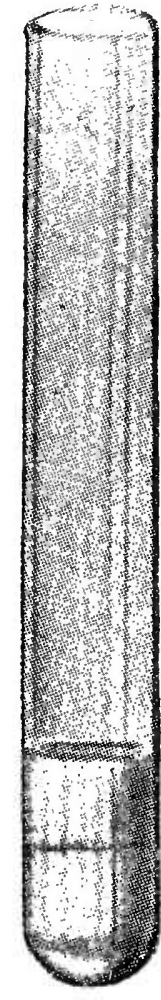

A

Tubo A - Reaçāo negativa.

Tubo B - Reação positiva.

Notar a presença de anel de precipitação.

(Roy Kracker). dadeiramente ativo e utilisavel em medicina legal, é indispensavel que determine, na temperatura die $37^{\circ} \mathrm{C}$., um precipitado completo, em vinte minutos a meia hora, em diluição, de $1 \mid 20.000$ e mais.

\section{4 - TÉCNICA DA REAÇÃO DE UHLENHUTH}

\section{(Sangue en Manchas)}

A reação da sôro precipitação só poderá praticar-se, uma vez feito o diagnóstico de certeza de sangue. Antes, portanto, de se determinar a origem do material, devese determinar a sua natureza, isto é, se é sangue. Chega-se ao diagnóstico de certeza, por meio das reações microcristalográficas e espectroscópicas.

A seguir, passa-se a macerar a mancha de sangue em solução fisiológica, afim de se obter um extrato de concentração a $1 \%$. $\mathrm{Na}$ prática não se possue processo rigoroso seguro, para se avaliar o gráu de concentração de uma mancha de sangue. Então, para isso, lança-se mão de meios empíricos e que permitem, mais ou menos, determinar-se aquele teor de concentração do extrato da mancha e que são os seguintes: a) Processo da gota de sangue. Sôbre uma folha de papel de filtro deixa-se cair uma gota de sangue que, uma vez absorvida, toma o tamanho de uma moeda de 400 reis das grandes. Corta-se na mancha de sangue um pedaço cujo tamanho seja igual ao da moeda de 400 reis e se põe a macerar em 6,25 c. c. de solução fisiologica de $\mathrm{NaCl}$ a $8,5^{\circ} \%$, por tempo que variará com a idade da mancha. As manchas muito antigas levam 24 a 48 horas para se dissolverem. Sabendo-se que 1 c. c. da solução fisiológica tem 16 gotás, em 6,25 c. c. ter-se-ão 100 gotas. Como se coloca uma quantidade de sangue equiva!ente a uma gota para macerar em $6,25 \mathrm{c}$ c. $=100$ gotas, segue-se que se está, mais ou menos, diante de uma concentração de extrato da mancha a $1 \%$. Para se obter uma concentração a $1 \%$, toma-se 1 c. c. da solução a $1 \%$, dilue-se em 9 c. c. da solução fisilológica de $\mathrm{NaCl}$ a $8,5^{\circ} \%$. 
b) Processo do ácido azótico a 25\%. - Num tubo de prova, colocam-se 2 c. c. da solução do extrato da mancha que se supõe a $1 \%$ oo, aquece-se e deita-se uma ou duas gotas da solução de ácido azótico a $25 \%$, que dará origem a um leve precipitado de colorido esbranquiçado (albumina) como na reação de Rivalta.

c) Processo da formação de espuma persistente: Êste prọcesso foi aconselhado por Uhlenhuth e Nutall que o recomendaram para avaliação da concentração de um extrato de mancha de sangue. Aqueles autores mandavam que se soprasse com uma pipeta capilar dentro do líquido em exame e, se houvesse sôro ou albumina no 'mesmo, formar-se-ia espuma persistente em sua superfície. $E^{\prime}$ mais prático agitar-se o tubo que contem a solução sanguínea ou de sôro. A presença de espuma tem menos valor para se dizer da concentração de uma albumina no líquido em exame do que de sua existencia. Todavia, a formação de espuma persistente na superfície do extrato da mancha indica, mais ou menos, a sua concentração a $1 \%$. A prova baseada no colorido do líquido tem valor, tambem, relativo, pois a côr depende da quantidade de hemoglobina presente, da matéria corante do tecido, da idade do sangue, do líquido empregado 'na maceração da mancha, da quantidade do sôro, etc.. Em sÍntese, uma solução de extrato de mancha de sangue, a $1 \%$, deve ter o colorido amarelo, formar espuma resistente, quando agitada, produzir 'um precipitado ao ser tratada por uma solução de ácido azótico a $25 \%$.

\section{5 - REAÇÃO DO MEIO}

E' de importância prática, antes de se adicionar o sôro precipitante antihumano à solução de extrato da mancha de sangue, cuja especificidade se vai determinar, achar-se a reação do meio, isto é, verificar se é ácido, alcalino ou neutro. Êsse cuidado é indispensavel, pois, em sendo o líquido ácido ou alcalino prejudica a reação. Entretanto, há autores, como Tchistowitch, que afirmam que a reação só se processa em meio alcalino. Quando neutro, o precipitado será escasso e, se ácido, a reação não se dará. Outros pensam que a acidez ou a alcalinidade do meio em nada inflúem no resultado da prova.

Entretanto, de acordo com a nossa experiência, achamos que a solução deve ser neutra ao turnasol. Se fôr alcalina será acidificada com uma solução diluida de ácido tartárico e, se ácida, alcalizada por uma solução diluida de carbonato de sódio. Para se avaliar, com rigor, a reação do meio, é oportuno determinar-se o seu $\mathrm{pH}$, cujo ótimo, conforme Fichon e Sannié, estará colocado entre $\mathrm{p} \mathrm{H}=7,2$ e $\mathrm{pH}=7,8$. 


\section{6 - MANEIRA DE SE PROCEDER A REAÇÃo}

Para se praticar a reação de Unlenhuth, tomam-se seis tubos de prova com $5 \mathrm{mms}$. de diâmetro e $1,5 \mathrm{c}$. c. de capacidade e assim se procede: No tubo n. 1 colocam-se U,9 c. c. do macerato da mancha diluido a $1 \%$, cuja especificidade se quer determinar e se adiciona 0,1 c. c. de sôro precipitante antihumano; fig. n. ${ }^{\circ} 10$.

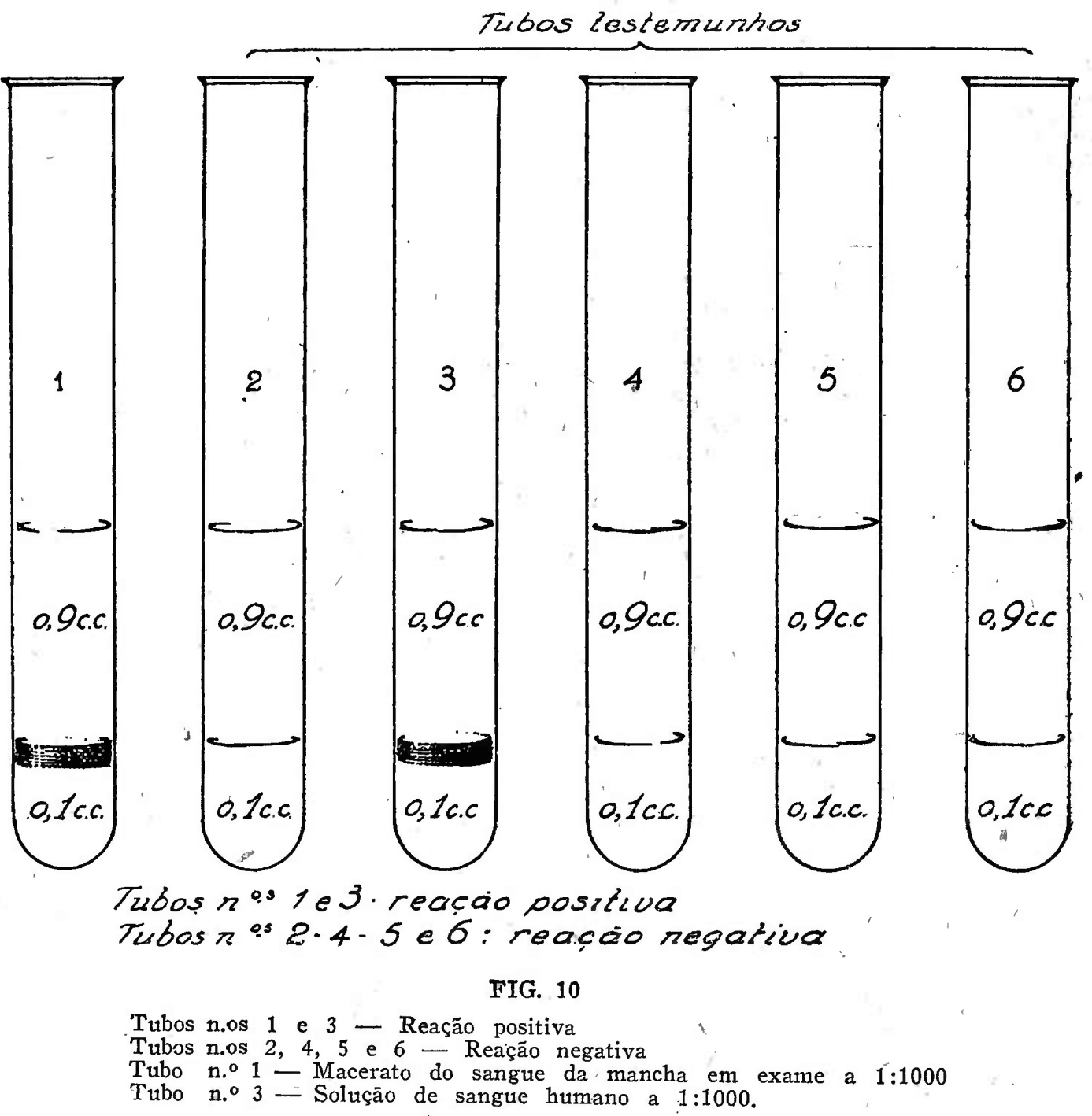

No tubo n. ${ }^{\circ} 2,0,9$ c. c. da solução de cloreto de sódio a $1 \%$, com qual se macerou a mancha de sangue e 0,1 c. c. precipitante antihumano;

No tubo n. ${ }^{\circ} 3,0,9$ c. c. ${ }^{*}$ duma solução de sangue humano a $1 \%$ e 0,1 c. c. de sôro precipitante antihumano;

No tubo n. ${ }^{\circ}$ 4, 0,9 c. c.: duma solução de sangue humano a $1 \%$ e 0,1 c. c. de sôro normal de um coelho que não foi injetádo;

No tubo n. ${ }^{\circ} 5,0,9$ c. c. duma solução a $1 \%$ oo de sangue dum coelho não inoculado e 0,1 c. c. de sôro precipitante antihumano; 
No tubo n. $6,0,9$ c. c. duma solução de macerato de úm pedaço de pano da mancha, porém retirađo dum ponto não manchado de sangue e 0,1 c. c. de sôro precipitante antihumano.

Os tubos são imediatamente levados à estufa a $37^{\circ} \mathrm{C}$., por vinte minutos à meia hora.

Depois dêste tempo, retiram-se os tubos da estufa e procede-se a leitura. Nos tubos $n .^{\circ}$ s 1 e 3 , se o material fôr de procedência humana, notar-se-á um precipitado de colorido branco, sob fórma de anel, no limite separativo dos líquidos em presença. Os tubos $2,3,4,5$ e 6 são para comprova de reação. O sôro precipitante fíca sempre no fundo do tubo, porque é mais denso que as soluções em exame. Figs. n. ${ }^{\circ}$ s 11 e 12.

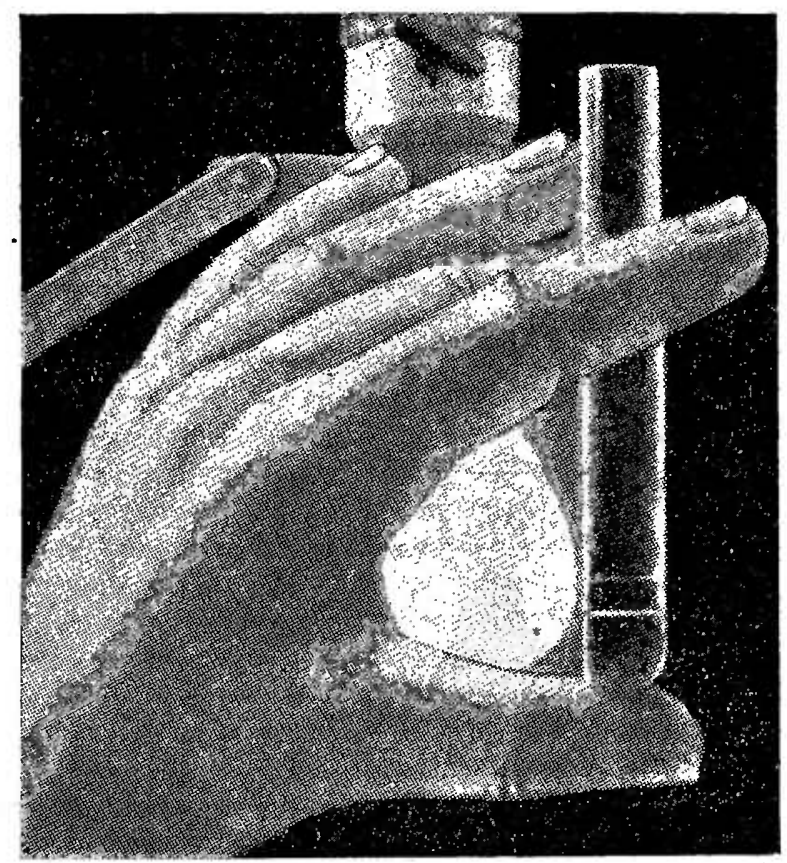

FIG. 11

Como se deve examinar o tubo em que houve precipitação. Observa-se o tubo contra um fundo escuro e tendo ao lado, uma lampada. eletrica de fraca intensidade.

(Roy Kracke).

\section{9 - PARTICULARIDADES INTERESSANTES DA REAÇÃO}

Há manchas de sangue que, a-pesar-de permanecerem 24 horas em maceração, não se dissolvem no sôro fisiológico. Isso se dá com maichas antigas submetidas à ação do calor, da luz, de agentes químicos. Essas manchas, todavia, podem dissolver-se noutros líquidos como o hidrato de potássio, de sódio, acido acético, etc. As proteinas do sangue resistem muito ao calor. Ferrari, em experiências interessantes, mostrou que as manchas deixam de reagir dêsde que submetidas ao calor de $130^{\circ}$ C. por uma hora, a $140^{\circ}$ C. por $20^{\prime}$,, 
a $150^{\circ} \mathrm{C}$. por $10^{\prime}$, a $160^{\circ} \mathrm{C}$. por $5^{\prime}$ a $10^{\prime}$. As proteinas resistem menos ao calor úmido que ao calớr sêco. Não se deve esquecer, todas às vezes que a mancha fôr macerada em líquido ácido ou alcalino, de neutralizar o macerato antes de realizar à prova. Em sendo a mancha insoluvel na solução fisiológica de cloreto de sódio a 8,5\% dissol-

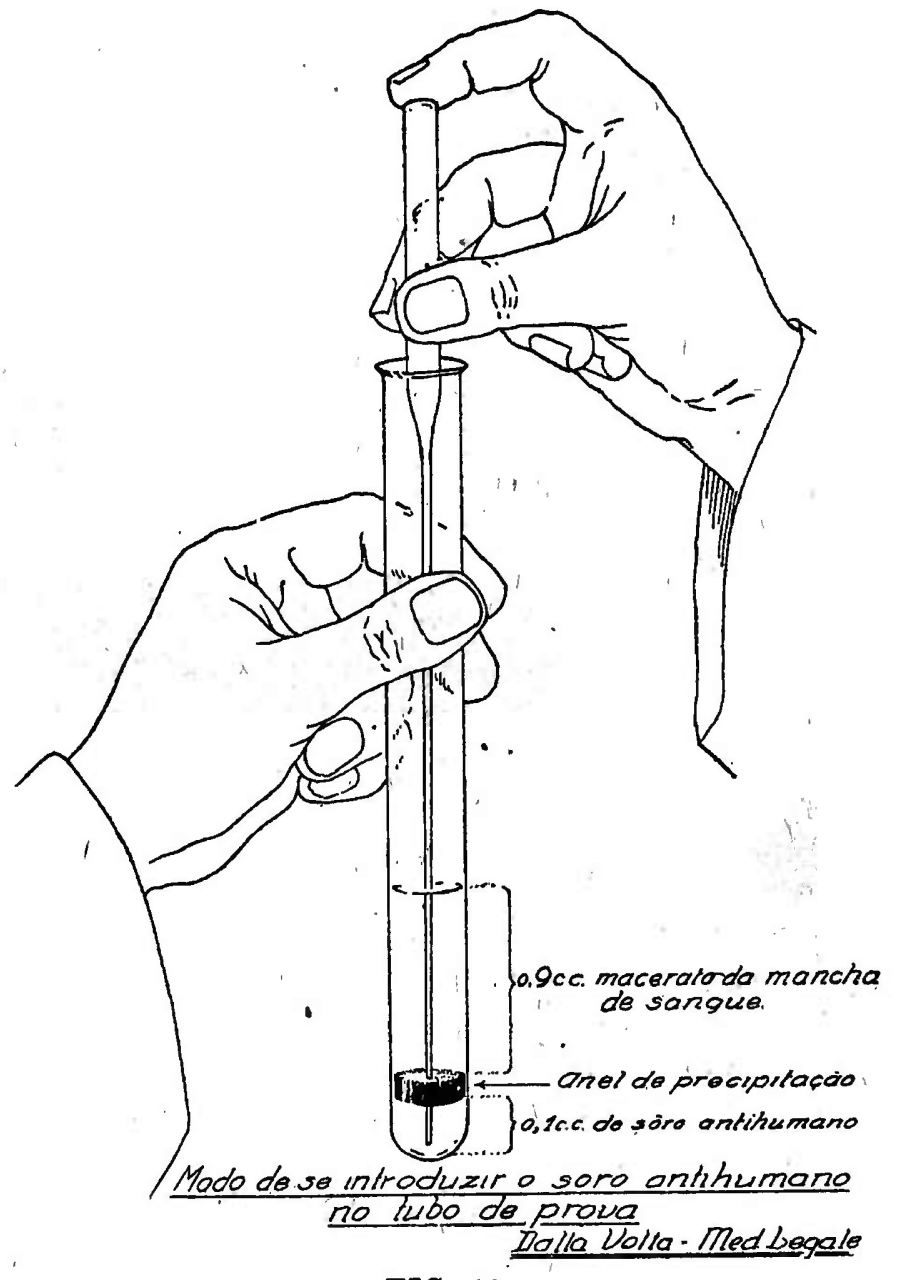

FIG. 12

ver-se-à numa solução diluida de hidrato de sódio. Nêsse casō, segundo Dalla Volta, as proteinas se alteram a ponto de reagirem com os antisôros obtidos de animais que foram inoculados com sôro da mesma espécie e tratados do mesmo modo. Com os antisôros comuns de espécies correspondentes não reagem. De fato, o tratamento a que se submete o antígeno crea nova especificidade sem que seja abolida a origináría.

O antígeno, para essas reações, é preparado do seguinte modo: A 60 c. c. de sôro adiciona-se igual quantidade de solução de cloreto de sódio a $8,5 \%$, que se aquecerá a banho maria a $70^{\circ} \mathrm{C}$.. A' solução acrescenta-se, pouco e pouco, 10 c. c. de outra normal de hidrato de potássio e tudo é aquecido a banho maria a $70^{\circ} \mathrm{C}$. por 15 a 20 minutos. O líquido obtido, pode ser injetado na veia marginal da orelha do coelho, sem necessidade de ser neutralizado: Tambem se 
pode neutralizar o líquido e injetar no peritônio do animal. Depois 5 a 10 inoculações de 10 c. c. de antígeno, obtem-se um sôro de bom título para a prova. No caso de se neutralizar o líquido, há formação de um precipitado flocoso que não prejudica e nem altera reação.

De outro lado, as manchas de sangue serão maceradas em solução $\mathrm{N} / 10$ de $\mathrm{Na} \mathrm{OH}$, contendo solução físiológica de $\mathrm{NaCI}$ a $8,5 \%$ e que será aquecida a banho maria, durante 15 a 20 minutos, a $60^{\circ}$ $\mathrm{C}$ a $70^{\circ}, \mathrm{C}$.

O macerato da mancha deve ser neutralizado com uma solução de $\mathrm{HCl}$. a $\mathrm{N} / 20$ e o líquido diluido com solução de $\mathrm{NaCl}$. em proporção tal que se obtenham as proteinas em determinada concentração. A reação será praticada seguindo-se a técnica já mencionada. No caso de manchas muito antigas, de quinze anos è mais, o antisôro preparado com os antígenos cozidos fornecem bons resultados. Dalla Volta, em seu excelente compêndio de Medicina Legal, recomenda para se dissolver manchas antigas o método de Ryo Tsukasaki, por êle modificado. "Macera-se uma mancha de sangue por seis horas numa solução de $\mathrm{NaOH}$ a $\mathrm{n} / 5$, contendo $0,85 \%$ de $\mathrm{NaCl}$. A maceração pode ser feita na geladeira ou tambem à temperatura do laboratório. A soluçăo será neutralizada com uma solução titulada de $\mathrm{HCl}$ deluida e filtrada. Tambem se pode proceder mais lentamente, colocando a mancha numa solução de $\mathrm{NaOH}$ a N/300 por 24 horas, sempre adicionada de $\mathrm{NaCl}$. A solução deve ser neutralizada e filtrada". As manchas que sofreram a ação de agentes quimicos variados e que atuam sôbre as poteinas, podem perturbar os resultados da prova. Em todo caso, tais manchas serão submetidas aos cuidados atrás mencionados.

Há agentes, segundo Dalla Volta, cuja ação varia conforme os casos, podendo' conduzir, evidentemente, á adulteração das proteinas. "Trata-se de um campo de pesquisas hoje estudado de modo incompleto, onde os dados fornecidos pela literatura são incertos e mesmo contraditórios".

\section{0 - COMO SE PRATICAR A REAÇÃO DE UHLENHUTH COM MANCHAS ESCASSAS}

Nos casos em que o perito possue mancha de sangue muito pequena, exígua, a prova não poderá praticar-se com tanta segurança como em caso oposto. Para fazê-la com maior segurança, os técnicos aconselham o método dos tudos capilares, que melhor resultado fornece na prática. Os tubos capilares podem ser preparados no próprio laboratório, lançando-se mão de tubos de vidro de 4 a $5 \mathrm{mms}$. de diâmetro e que serão destinados para êste fim. A técnica é a seguinte:

a) Tomam-se dois vidros de relógios e com pipetas diferentes colocam-se, em cada um dêles, uma gota de antisôro humano e outra de extrato dá mancha a estudar-se. 
b) O extrato da mancha será feito cuidadosamente e por maceração durante 12 a 14 horas, em solução de cloreto de sódio a $8,5^{\circ} \%$, bem concentrado.

c) Se a temperatura fôr elevada, a maceração será feita na geladeira e depois o extrato será centrifugado.

d) Deixa-se secar uma gota de extrato concentrado em vidro de relógio para a pesquiza do hemocrogênio (Reação espectroscópica ou microcristalográfica) :

e) $\mathrm{O}$ extrato é depois diluido a $1 \%$ e verificado pelos processos conhecidos:

f) Toma-se um tubo capilar e se submerge uma de suas extremidades na gota do extrato da' mancha que é obsorvida, em parte; por capilaridade. Noutro vidro de relogio coloca-se uma gota de sôro antihumano e se faz o líquido entrar no tubo, evitando que se misturem. Quando penetrou no tubo a quantidade de líquido necessária, deve-se manter o dedo obliterando a extremidade oposta, afim de evitar a entrada de ar no mesmo e o refluxo do líquido.

11 - Uma vez entroduzido o sôro precipitante, a extremidade livre do tubo será fechada com cêra. Os tubos de prova serão feitos com muito cuidado. No limite separativo dos líquidos forma-se o precipitado.

\section{2 - VALOR MÉDICO LEGAL DA REACÃO DE UHLENHUTH}

Como já se disse anteriormente, a reação de Uhlenhuth não diz da natúreza de uma proteina, mas, somente, serve para assinalar a presença de uma albumina determinada.

Portanto, antes de mais nada, é necessário precisar-se, pelas reações micro-cristalográficas ou espectroscópicas, que se está perante uma mancha de sangue e, só depois, é que se fará a prova biológica.

A-demais, como é sabído, em sendo positiva a prova, a sua especificidade não é absoluta, mas, sim, relativa.

$\mathrm{E}$ isso, porquc, conforme demonstrou Nútall, um sôro de màmífero, por exemplo, de alto poder precipitante, reage com sangue de mamíferos em baixa diluiçạ̃o, isto é, a $1 \%$, a $1 / 200$, a $1 / 300$. Tambem, o sôro precipitante de tÍtulo elevado, de determinada espécie animal, precipita as proteinas das espécies que lihe são aparentadas, próximas. Isso, porém, quando os sôros das espécies com experiência estiverem em diluições baixas. Assim, por exemplo, um antisôro de cavalo precipita o sôro ou sangue de burro e de jumento, além de precipitar o sôro de cavalo. $\mathrm{O}$ sôro antihumano age, da mesma fórma, com o. sangue dos macacos superiores e com o sangue humaño. Estas reações que se verificam entre espécies 
proximas, são denóminadas de reações de grupo. Ora, em medicina legal é indispensavel que se faça a distinção entre uma reação de grupo e uma espécifica, afim de se evitarem erros perigosos. Para isso, existem vários meios preconisados e, entre êles, como os melhores, citaremos três.

1. ) O da absorpção específica de Weichert;

$\left.2 .^{\circ}\right)$ O da deluição alta do antígeno;

3..$^{\circ}$ E o da velocidade da reação precipitante.

O primeiro consiste em se fazer atuar o antisôro com o sôro da espécie que se deseja evitar a reação de grupo e remover-se o precipitado que se formara. O sôro que restar só reagirá com o sôro do animal com que fôra imunizado. $\mathrm{O}$ antisôro de vaca, por exemplo, misturado ao de cabra, formará um precipitado que, removido, deixará um sôro que só precipitará o sangue de vaca. O mesmo acontecerá com o antisôro humano para o sangue dos macacos superiores.

O segundo processo, o mais uzado na prática médico legal, consiste em se diluir o antígeno altamente, a $1 \%$, fazendo-o reagir com antisôro cujo título não seja inferior a $1 / 20.000$.

O terceiro processo é aquele fornecido pela velocidade da reação precipitante. Um sôro precipitante de título elevado, $1 / 20.000, \ldots$. $1 / 30.000$, etc., reage rapidamente com o sôro da espécie animal com que fôra imunizado e vagarosamente com os das espécies afins.

Aí, ' pois, a razão da leitura da reação precipitante ser feita dentro 'de $20^{\prime}$ a $1 / 2$ hora, na estufa a $37^{\circ}$. Todo precipitado que se formar depois dêste tempo não terá valor.

$\mathrm{Na}$ prática forense, o legista raramente terá que se avir com uma reação de grupo, pois o sangue de macacos superiores dificilmente se encontrará.- Em todo caso, o cuidado com as simulações deve ser observado. A-demais, com os processos atrás mencionados, essas causas prováveis de êrro são evitadas. Há outras causas de êrro que - legista deve conhecer e saber como afastá-las. Assim, a solução, a-pesar-de todos cuidados técnicos, pode permanecer turva, mesmo que centrifugada e filtrada, devido a contaminação microbiana simulando verdadeiro precipitado. Nesse caso, a observação imediata do resultado, quando postos em contacto sôro e antisôro, evita uma interpretação errônea. De outro lado, se a prova de Uhlenhuth pode ser aplicada na maioria dos casos, não o será sempre a todos, pois há fatores que a podem impedir. Numa mesma mancha, ainda, pode-se encontrar mistura de albuminas de várias espécies animais e que dificultará o resultado da reação e impossibilitará a determinação da origem da mesma. Assim sendo, o legista terá presente tôdas essas possibilidades de êrro e será muito prudente em suas conclusões. Depois de mencionar que diagnosticou sangue, é necessário não afirmar peremptóriamente a sua especificidade, mesmo que obtenha uma 
reação positiva "com o sôro precipitante e sangue humano, por exemplo, que tenha certeza de estar em presença de sangue humano, o que seria cometer uma falta. Dirá simplesmente, que o sangue estudado deu, com o sôro precipitante, as mesmas reações que com sangue humano. $\mathrm{O}$ perito, assim respondendo, fará restrição quanto à especificidade da-reação e, mais tarde, se necessário fôr, explicará aos magistrados, aos jurados, as razões de sua prudência e de sua reserva. 